\title{
AESTHETICS AND STYLE IN STRATEGY
}

Edited by Gino Cattani, Simone Ferriani,

Frédéric Godart and Stoyan V. Sgourev

ADVANCES IN STRATEGIC MANAGEMENT

VOLUME 42 


\section{AESTHETICS AND STYLE IN STRATEGY}




\section{ADVANCES IN STRATEGIC MANAGEMENT}

\section{Series Editor: Gino Cattani}

Previous Volumes:

Volume 20: Geography and Strategy

Edited by: Joel A. C. Baum and Olav Sorenson

Volume 21: Business Strategy over the Industry Lifecycle

Edited by: Joel A. C. Baum and Anita M. Mcgahan

Volume 22: Strategy Process

Edited by: Gabriel Szulanski, Joe Porac and Yves Doz

Volume 23: Ecology and Strategy

Edited by: Joel A. C. Baum, Stanislav D. Dobrey and Arien van Witteloostuijn

Volume 24: Real Options Theory

Edited by: Jeffrey J. Reuer and Tony W. Tong

Volume 25: Network Strategy

Edited by: Joel A. C. Baum and Tim J. Rowley

Volume 26: Economic Institutions of Strategy

Edited by: Jackson A. Nickerson and Brian S. Silverman

Volume 27: Globalization of Strategy Research

Edited by: Joel A. C. Baum and Joseph Lampel

Volume 28: Project-based organizing and Strategic Management

Edited by: Gino Cattani, Simone Ferriani, Lars Frederiksen and Florian Taube

Volume 29: History and Strategy

Edited by: Steven J. Kahl, Brian S. Silverman and

Michael A. Cusumano

Volume 30: Collaboration and Competition in Business Ecosystems

Edited by: Ron Adner, Joanne E. Oxley and Brian S. Silverman

Volume 31: Finance and Strategy

Edited by: Belen Villalonga 
Volume 32: Cognition and Strategy

Edited by: Giovanni Gavetti and William Ocasio

Volume 33: Business Models and Modelling

Edited by: Charles Baden-Fuller and Vincent Mangematin

Volume 34: Strategy Beyond Markets

Edited by: John M. Figueiredo, Michael Lenox,

Felix Oberholzer-Gee and Richard G. Vanden Bergh

Volume 35: Resource Redeployment and Corporate Strategy

Edited by: Timothy B. Folta, Constance E. Helfat

and Samina Karim

Volume 36: Geography, Location, and Strategy

Edited by: Juan Alcacer, Bruce Kogut, Catherine Thomas, Bernard Yin Yeung

Volume 37: Entrepreneurship, Innovation, and Platforms

Edited by: Jeffrey Furman, Annabelle Gawer,

Brian S. Silverman and Scott Stern

Volume 38: Sustainability, Stakeholder Governance \& Corporate Social Responsibility

Edited by: Sinziana Dorobantu, Ruth V. Aguilera, Jiao Luo and Frances J. Milliken

Volume 39: Behavioral Strategy in Perspective

Edited by: Mie Augier, Christina Fang, Violina Rindova

Volume 40: Organization Design

Edited by: John Joseph, Oliver Baumann, Richard Burton, Kannan Srikanth

Volume 41: Employee Inter- and Intra-Firm Mobility: Taking Stock of What We Know, Identifying Novel Insights and Setting a Theoretical and Empirical Agend

Edited by: Bruno Cirillo and Daniel Tzabbar 
This page intentionally left blank 


\title{
AESTHETICS AND STYLE IN STRATEGY
}

\author{
EDITED BY \\ GINO CATTANI \\ Leonard N. Stern School of Business, USA
}

SIMONE FERRIANI

University of Bologna, Italy

FRÉDÉRIC GODART

INSEAD, France

STOYAN V. SGOUREV

ESSEC Business School, France

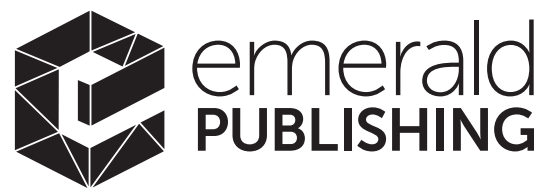

United Kingdom - North America - Japan

India - Malaysia - China 
Emerald Publishing Limited

Howard House, Wagon Lane, Bingley BD16 1WA, UK

First edition 2021

Copyright (C) 2021 Emerald Publishing Limited.

1. Introduction 'The Aesthetic Turn in Strategy: Creating Value with Style'

(C) Gino Cattani, Simone Ferriani, Frédéric Godart, and Stoyan V. Sgourev. Published

by Emerald Publishing Limited. This chapter is published under the Creative

Commons Attribution (CC BY 4.0) licence. Anyone may reproduce, distribute,

translate and create derivative works of this article (for both commercial \& non-commercial purposes), subject to full attribution to the original publication and authors. The full terms of this licence may be seen at http://creativecommons.org/licences/by/4.0/legalcode.

2. Chapter 6 'Tell Me Your Story and I Will Tell Your Sales: A Topic Model Analysis of Narrative Style and Firm Performance on Etsy' (C) Donato Cutolo, Simone Ferriani, and Gino Cattani. Published by Emerald Publishing Limited. This chapter is published under the Creative Commons Attribution (CC BY 4.0) licence. Anyone may reproduce, distribute, translate and create derivative works of this article (for both commercial \& non-commercial purposes), subject to full attribution to the original publication and authors. The full terms of this licence may be seen at http://creativecommons.org/licences/by/4.0/legalcode.

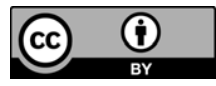

\section{Reprints and permissions service}

Contact: permissions@emeraldinsight.com

No part of this book may be reproduced, stored in a retrieval system, transmitted in any form or by any means electronic, mechanical, photocopying, recording or otherwise without either the prior written permission of the publisher or a licence permitting restricted copying issued in the UK by The Copyright Licensing Agency and in the USA by The Copyright Clearance Center. Any opinions expressed in the chapters are those of the authors. Whilst Emerald makes every effort to ensure the quality and accuracy of its content, Emerald makes no representation implied or otherwise, as to the chapters' suitability and application and disclaims any warranties, express or implied, to their use.

British Library Cataloguing in Publication Data

A catalogue record for this book is available from the British Library

ISBN: 978-1-80043-237-6 (Print)

ISBN: 978-1-80043-236-9 (Online)

ISBN: 978-1-80043-238-3 (Epub)

ISSN: 0742-3322 (Series)

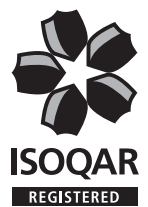

ISOQAR certified

Management System,

awarded to Emerald

for adherence to

Environmental

standard

ISO 14001:2004.

Certificate Number 1985

ISO 14001

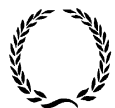

INVESTOR IN PEOPLE 


\section{CONTENTS}

List of Figures and Tables ix

About the Authors xiii

Foreword xix

The Aesthetic Turn in Strategy: Creating Value with Style 1 Gino Cattani, Simone Ferriani, Frédéric Godart and Stoyan V. Sgourev

\section{PART I STYLISTIC PRODUCTION}

Style Typologies and Competitive Advantage

Giovanni Formilan

Aesthetic and Technological Complexity in Luxury

Watchmaking

Frédéric Godart, Kim Claes and Stoyan V. Sgourev

From Style to Status and to Power: When and Why Do Stylistic Choices in Footwear Make Women Feel and Act Powerful?

David Dubois and Lalin Anik

Content or Connections? Socio-Semantic Analysis of Leaders' Communication Styles in a Creative Collective

Nikita Basov, Artem Antonyuk and Iina Hellsten

Tell Me Your Story and I Will Tell Your Sales: A Topic Model Analysis of Narrative Style and Firm Performance on Etsy

Donato Cutolo, Simone Ferriani and Gino Cattani 


\section{PART II \\ STYLISTIC EVALUATION}

A Rising Tide Lifts all Boats: The Origins of Institutionalized Aesthetic Innovation

Micki Eisenman and Tal Simons

Changing Style in Style-changing Industries: The Role of Critics as Gatekeepers in High-end Fashion

Paola Cillo, Joseph C. Nunes, Emanuela Prandelli and Irene Scopelliti

Does Stylistic Similarity to Popular Competitors Affect Consumer Evaluations of Quality? Evidence from Online Movie Evaluations 199 Daniel B. Sands

Strategic Balance or Imperfect Imitation? Style and Legitimation Challenges in a Semi-peripheral City Alexander D. Hoppe

\section{PART III \\ REFLECTIONS ON STYLE}

Reflections on Style and Strategy: An Interview with Candace Jones

Candace Jones

Reflections on Style and Strategy: An Interview with Gianni

Lorenzoni

Gianni Lorenzoni

Reflections on Style and Strategy: An Interview with Virginia Postrel

Virginia Postrel

Reflections on Style and Strategy: An Interview with Davide Ravasi

Davide Ravasi

Reflections on Style and Strategy: An Interview with Antonio Strati

Antonio Strati

Index 


\section{LIST OF FIGURES AND TABLES}

Figure 1. Different Combinations of Form and Content Dimensions of Style Configure Coherent and Incoherent Style Typologies.

Figure 2. Outline of the Computer-assisted Routine Used to Manipulate Photographic Material.

Figure 3. Map of Electronic Music Sub-genres, with Values Assigned to the Main Sub-genres in the Sample.

Figure 4. Distribution of Relevant Measures and Style Typologies in the Sample.

Figure 5. Decile-wise Ranking Distribution of Each Style Typology (Percentages Represent within-group Proportions).

Figure 1. Hypothesized Impact of Aesthetic and Technological Code Complexity on Lay and Professional Evaluation. $\quad 56$

Figure 1. US Search Rates for 'Heels', 'Pumps', 'Slides' and 'Sneakers' (2008-2018; Google shopping searches).

Figure 2. US Search Rates for 'Heels' and 'Fashion Show' (2008-2018; Google Web Searches).

Figure 3. Shoes Used (Sample), Studies 1 and 3.

Figure 4. Perceived Power and Perceived Status as a Function of Shoe Style, Study 1.

Figure 5. Choice Set, Study 2.

Figure 6. Action Orientation Score as a Function of Shoe Style and Social Visibility, Study 3.

Figure 7. Abstraction Score as a Function of Shoe Style and Social Visibility, Study 3.

Figure 1. Social Network Structure of the Group. 108

Figure 2. Semantic Content Shared with Integrator. 110

Figure 3. Semantic Content Shared with Critic and Integrator. Link width scaled according to frequency of association; complexity of the component reduced in the main picture, full component displayed in the lower right.

Figure 1. Topics Distribution and Narrative Conventionality: An Illustration of Two Cases. 
Figure 2. Narrative Conventionality - Craft Items Sold Relationship. Marginal Effects Estimated by Keeping the Other Covariates at Their Means.

Figure 1. Predicted Probabilities of Consumer Evaluations for Movies During Opening Week of Release.

Figure 2. Predicted Probabilities of Consumer Evaluations for Movies after Opening Week of Release.

Figure 1. Imperfect Imitation in the Semi-periphery.

Table 1. Overview of the Regression Models Used to Test the Hypotheses (Method, Dependent Variable and Main Regressors).

Table 2. Descriptive Statistics and Pearson Correlation Matrix $(N=100)$.

Table 3. Odds of Being Visually Garish.

Table 4. Influence of Style Typologies on the Likelihood (Model 6 and 7) and Progressive Odds (Model 8) of Occupying a Higher Position in the Ranking.

Table 5. Quantile Regression Predicting the Likelihood of Occupying a Higher Position in the Ranking.

Table 1. Descriptive Statistics and Pearson Correlation Coefficients.

Table 2. Multilevel Mixed-Effects Logistic Regression on Public Awards (Evaluation by Laypersons).

Table 3. Multilevel Mixed-Effects Logistic Regression on Professional Awards (Evaluation by Professionals).

Table 1. Individual Intensity of Communication.

Table 2. Contribution to Semantic Content.

Table 3. Properties of Semantic Content with and without Contribution by One of the Leaders.

Table 4. Properties of Semantic Content with Two Leaders and without Leaders.

Table 1. Two Examples of Narrative-topics Distribution.

Table 2. Descriptive Statistics and Correlation Matrix.

Table 3. Negative Binomial Regression Models.

Table 1. Fashion Houses in Paris and Milan (Sponsoring at Least Five Catwalks from 1999 to 2007).

Table 2. Summary Statistics of Independent Variables.

Table 3. Elements of the Style Genome: Continuous Variable Coding (By Garment Type). 
Table 4. Elements of the Style Genome: Discrete Variable Coding (For All Garments).

Table 5. Average Style Distance as a Function of Year Span.

Table 6. Logistic Regression of Review Meanrating on Designer's (or Design Team) Change $(N=525)$.

Table 7. Within Designer Regression of Review Meanrating on Individual Designer's Style Distance between Two Seasons.

Table 8. Across Designers Regression of Other Designers' Reviews on Individual Designer's Style Distance between Two Seasons.

Table 1. Movie Descriptive Statistics and Correlation Matrix for Selected Variables.

Table 2. Consumer Evaluations for Movies During Opening Week of Release.

Table 3. Consumer Evaluations for Movies During Opening Week of Release.

Table 4. Count of Consumer Evaluations for Movies.

Table 5. Consumer Evaluation for Movies During Opening Week of Release with Demand Residual.

Table 6. Consumer Evaluation for Movies after Opening Week of Release with Demand Residual.

Table 1. Sources and Signals of Legitimacy. 234

Table 2. Research Participants. 
This page intentionally left blank 


\section{ABOUT THE AUTHORS}

Lalin Anik is an Assistant Professor of Marketing at University of Virginia's Darden School of Business. As an expert in the science of behavior change, she combines insights from psychology and economics to tackle big business and societal problems. Lalin has worked closely and consulted with major companies, organizations and governments to design novel social interventions that help consumers, employees and communities make better decisions and lead healthier, happier and more productive lives. As an award-winning teacher, Lalin was named as the "2019 MBA Professor of the Year" as well as one of the "2019 Best 40 Under 40 MBA Professors" by Poets \& Quants. She holds a doctorate of business administration degree in marketing from Harvard Business School and a B.A. degree in psychology and business from Brandeis University

Artem Antonyuk, MA, is an affiliated Researcher at the Centre for German and European Studies, St. Petersburg University. His research interests include freedom of speech, internet governance and applications of semantic network analysis in the study of knowledge creation.

Nikita Basov is both Senior Researcher in Sociology and Scientific Manager of the Centre for German and European Studies at St. Petersburg University. He investigates the fundamental principles of socio-cultural microdynamics. The main method is multidimensional - socio-semantic and socio-material - network analysis, with a particular focus on mixing ethnography with statistical modelling. His papers appeared in Social Networks, Poetics, and American Journal of Cultural Sociology. He is also the organizer of the conference series 'Networks in the Global World' in St. Petersburg and of 'St Petersburg Summer School on Network Analysis'.

Gino Cattani is Professor of Strategy and Organization Theory at the Stern School of Business, New York University. He received his $\mathrm{PhD}$ in business administration from the Wharton School of Management, University of Pennsylvania. His research focuses on creativity, innovation, and social evaluation. His work has been featured in leading academic journals such American Sociological Review, Administrative Science Quarterly, Organization Science, Strategic Management Journal, Academy of Management Journal, Strategy Science, Research Policy and Industrial and Corporate Change. He won the 2012 Richard Nelson Award. He served as Senior Editor at Organization Science, and is currently Associate Editor at Management Science and Industrial and Corporate Change, and the Editor for Advances in Strategic Management.

Paola Cillo is an Associate Professor of Management, Vice Director of the Department of Management and Technology at Bocconi University, and Director of the Concentration in Luxury Business Management of the MBA 
Program at the SDA Bocconi School of Management. She is also a member of the Gucci Research Lab, funded by Gucci at Bocconi University and focused on research on innovation in creative organizations. Her research examines the dynamics of innovation in creative industries, investors' reaction to innovation, and big data and innovation. She received a $\mathrm{PhD}$ in Management from Bocconi University. Her research has been published in leading international journals, such as Journal of Marketing, Research Policy, Journal of Product Innovation Management.

Kim Claes is an Assistant Professor of management at the Sungkyunkwan Graduate School of Business. He received his $\mathrm{PhD}$ from INSEAD. His research interests include venture capital, blockchain, and luxury industries, with a particular emphasis on the socio-structural determinants of prices and valuation in those markets.

Donato Cutolo is a Postdoctoral Research Fellow at the University of Bologna and a PhD candidate in Management at the University of Bologna. He has been a visiting scholar at the MIT Sloan School of Management. His research touches upon several areas at the intersection of economic sociology, entrepreneurship, and strategic management, including: (1) social evaluation processes of atypical and unconventional actors; (2) narratives and linguistic; (3) digital platforms and entrepreneurial dynamics. In his latest project, he is using a mix of quantitative analysis and topic models to investigate how atypical crafters selling their products on digital platforms can leverage different narrative strategies to elicit market attention.

David Dubois (PhD, Kellogg School of Management) is an Associate Professor and the Cornelius Grupp Fellow in Digital Analytics for Consumer Behaviour at INSEAD. David's expertise bridges "big" data analytics, digital transformation and luxury and fashion brand management. A 2017 Young Scholar by the Marketing Science Institute, David is among the top 40 bestselling case authors worldwide and his cases on L'Oréal Paris' big data and analytics strategy and the customer experience makeover at AccorHotels won the 2017 and 2018 best marketing case awards, respectively. A passionate educator, he helps professionals and organizations to leverage style and status dynamics in the marketplace to build long-term competitive advantages. He has designed, directed and delivered dozens of executive education programs for companies such as Cartier, Google, or Moët Hennessy to name a few and also teaches MBA electives on Value Creation in Luxury and Fashion and (2) Digital and Social Media Strategy. A global citizen, David grew up in France and has lived in the USA (Chicago) and Japan. He currently lives in Singapore with his wife and two kids.

Micki Eisenman is Senior Lecturer in the Organizational Behavior and Strategy groups at TheHebrew University's Jerusalem School of Business, and was a Visiting Professor at the Robert H. Smith School of Business at The University of Maryland. Prior to that, she was Assistant Professor at the City University of New 
York's Baruch College. She received her undergraduate degree in English and Communications from The Hebrew University, her MBA. from Tulane University, and her PhD in Management from Columbia University. Her research applies a constructivist perspective that examines how material forms shape meaning in institutions and how new meanings emerge in the context of organizations' aesthetic innovation efforts. In other work, she examined how organizations communicate by using aesthetic design. Her work has appeared in the Academy of Management Review, Administrative Science Quarterly, Journal of Management Studies, Research in the Sociology of Organizations, Long Range Planning, Human Relations, and the Journal of Developmental Entrepreneurship.

Simone Ferriani is Professor of Entrepreneurship at the University of Bologna and Honorary Professor at Cass Business School. His research interests include entrepreneurship, creativity, and social networks. He has published his work in journal articles, books and book chapters. Recent publications have focused on processes of social evaluation, the origin of entrepreneurship and the social side of creativity. He is a lifetime member of Clare-Hall College in Cambridge.

Giovanni Formilan is Lecturer in Creative Industries at the University of Edinburgh Business School, UK. His research focuses on creativity and innovation dynamics, with particular attention on the processes of development, classification and reception of creative identities. His interest in diverse analytical strategies has led him to develop research agendas that involve a variety of qualitative and quantitative methodological approaches for data analysis. He received his $\mathrm{PhD}$ in General Management from the University of Bologna, and has been a research fellow at the Centre for Interdisciplinary Methodologies at the University of Warwick, UK.

Frédéric Godart is an Associate Professor of Organizational Behavior at INSEAD in France. He received his PhD from Columbia University in the City of New York. He holds an MPhil in Social and Political Sciences from the University of Cambridge (Trinity College) in the UK, an MSc in Management from Sciences Po Paris, and was a fellow of the ÉcoleNormaleSupérieure in France. His research explores the dynamics of the creative industries and has appeared in the Academy of Management Journal, Organization Science, and the Strategic Management Journal among others. He is the author of Unveiling Fashion (2012, Palgrave-MacMillan).

Iina Hellsten is an Associate Professor at the Corporate Communication program group of the Amsterdam School of Communication Research, ASCoR. Her research focuses on the dynamics of communication networks, in particular in social media settings. Previously, she has hold positions as a post-doctoral researcher at ASCoR, researcher at the Royal Dutch Academy of Arts and Sciences (KNAW), and an assistant and associate professor at the VrijeUniversiteit Amsterdam. Her work has been published in communication sciences (e.g. in Science Communication, New Media \& Society, Journal of Computer- 
Mediated Communication) and in information sciences (e.g. in JASIST and Internet Research).

Alexander D. Hoppe is a $\mathrm{PhD}$ Candidate in Sociology at the University of Pennsylvania. His research covers social psychology, administration, and the economic mediations of creative work. His ethnographic dissertation analyzes organizational routines and ambidexterity across the apparel global value chain, centering on first-tier suppliers in India.

Candace Jones is the Chair of Global Creative Enterprise at the University of Edinburgh Business School. She has published in top journals on architecture, cities, film and music, using theoretical lenses of vocabularies, institutional theory, materiality and social networks. She was Chair of Organization and Management Theory division of the Academy of Management from 2012-2016. She co-edited the Oxford Handbook of Creative Industries (2015). She is on two U.K. Arts and Humanities Research Council grants: (1) Creative Informatics: Data Driven Innovation for the Creative Industries led by the University of Edinburgh; and (2) Policy and Evidence Center for Creative Industries led by NESTA. From 2014-2016, along with co-investigators she was awarded a grant of $\$ 797,529$ to study "The Impact of Material Artifacts and Visual Representations on the Institutionalization of Innovations"bythe Danish Council for Independent Research.

Gianni Lorenzoni is Professor Emeritus of Strategic Management University of Bologna and Honorary Visiting Professor at City, University of London. His research interests include strategic networks, design driven innovation, industry emergence and genealogical theories of entrepreneurship. Prof. Lorenzoni was the founding president of Bologna Business School (2000-2014), founding president of AlmaCube (2000-2010), vice president of the Italian Academy of Management (1991-1998) and chair of the Management Department of the University of Bologna (1991-1994). He served as advisory board member of several multinational companies (1983-2006).

Joseph C. Nunes is Professor of Marketing at the University of Southern California's Marshall School of business and holds the Joseph A. DeBell Endowed Professorship in Business Administration. He is widely known for his research on cultural goods including music, luxury goods and fashion, as well as his work on authenticity, loyalty programs, branding, and pricing. Prof. Nunes has published numerous papers in the top marketing journals including the Journal of Marketing Research, Journal of Consumer Research, Marketing Science, Journal of Marketing, International Journal of Research in Marketing and the Journal of Consumer Psychology. He has also published in journals outside of marketing such as Musicae Scientiae and Psychological Science. Prof. Nunes has written for the Harvard Business Review and other publications targeted to practitioners. He currently serves on the Editorial Boards of the Journal of Consumer Research, Journal of Marketing and the Journal of Consumer Psychology. Prof. Nunes received his $\mathrm{PhD}$ in Marketing as well as his MBA from the University of Chicago. 
Virginia Postrel is an Author and Bloomberg Opinion Columnist with a particular interest in the intersection of culture and commerce. Her latest book is The Fabric of Civilization: How Textiles Made the World (Basic Books, 2020). She is the author of The Power of Glamour (Simon \& Schuster, 2013), The Substance of Style (HarperCollins, 2003), and The Future and Its Enemies (Free Press, 1998). She lives in Los Angeles.

Emanuela Prandelli is an Associate Professor of Management at Bocconi University, and LVMH Associate Professor of Fashion and Luxury Management at Bocconi University. She is the Director of the Master in Fashion, Design, and Experience Management (MAFED). Her research focus regards fashion and luxury management, collaborative marketing, social media marketing, e-business, and the process of innovation. She published several international articles in leading international journals, such as Journal of Marketing, Journal of Marketing Research, Organization Studies, and Journal of Business Venturing. She received her $\mathrm{PhD}$ in Management from Bocconi University.

Davide Ravasi is Professor of Strategy and Entrepreneurship at the UCL School of Management, University College London. His research primarily examines how culture, identity, history and memory affect strategic and organizational changes, or are affected by them. He is interested more generally in cultural processes shaping entrepreneurship, design, and innovation.

Daniel B. Sands is a doctoral candidate in strategy and organization theory at the Leonard N. Stern School of Business, New York University. His primary research interests include the role of third parties in shaping market outcomes, and in particular the role of third party evaluators in the creation and capture of value. In his work, he addresses topics such as evaluation, valuation, price, competition, and innovation.

Irene Scopelliti is Professor of Marketing and Behavioural Science at City, University of London. Her research examines the influence of a variety of psychological factors on human judgments and decisions. She received a $\mathrm{PhD}$ in Management from Bocconi University, and was previously a Post Doctoral Research Fellow at Carnegie Mellon University. Her research has been published in leading journals including Management Science, Psychological Science, Journal of Consumer Psychology, International Journal of Research in Marketing, Journal of Product Innovation Management, and has been featured by major news organizations including Forbes, Time Magazine, BBC News, and the New York Times.

Stoyan V. Sgourev is Professor of Management at ESSEC Business School, France. He received his $\mathrm{PhD}$ in sociology from Stanford University and was a postdoctoral fellow at MIT Sloan. His research interests include innovation and evaluation practices in the creative industries and network dynamics in historical perspective. His work has been featured in leading organizational and 
sociological journals, such as American Sociological Review, Academy of Management Journal and Organization Science.

Tal Simons is a Professor of Organization Theory at the Rotterdam School of Management, Erasmus University. She received her PhD from the ILR School, Cornell University. Her research interests include creative processes and dynamics, and aesthetic innovation, the motivations and implications of organizations' use of symbols eliciting time and history, as well as questions pertaining to contestation and ideology. Tal employs qualitative and quantitative methodologies and studies varied contexts including the cultural sector (e.g., artistic dance), contested industries (e.g., tobacco industry) and organizational misconduct (e.g., corporate fraud). Her work has been published in the Academy of Management Journal, Administrative Science Quarterly, Management Science, and Organization Science among others.

Antonio Strati, Senior Professor at the Department of Sociology and Social Research, University of Trento, Italy, and ChercheurAssocié at the Centre de RechercheenGestion (i3-CRG), CNRS, ÉcolePolytechnique, IP Paris, is both a sociologist and an art photographer. He is a founder member of the Research Unit on Communication, Organizational Learning and Aesthetics (RUCOLA) at Trento and also a founder member of the SCOS, the Standing Conference on Organizational Symbolism. His book Organization and Aesthetics (Sage, 1999), one of the founding texts of the field, has been translated in several languages. He is also author of Theory and Method in Organization Studies (Sage, 2000) published also in Italian (NIS, 1996; Carocci, 2004) - and co-author (with Silvia Gherardi) of Learning and Knowing in Practice-Based Studies (Elgar, 2012). In 2018 he co-edited a special issue of Organization Studies on "Organizational creativity, play and entrepreneurship", and has just published Organizational Theory and Aesthetic Philosophies (Routledge, 2019). His artistic research in conceptual photography, Photopoesia, has been published in books and photographic journals, and collected at museums and international collections. 


\section{FOREWORD}

It is a significant coincidence and a propitious auspice that the publication of the ASTM 42 volume is devoted to the role of aesthetics and style in management. The volume marks the 100th anniversary of the Bauhaus movement, born in Dessau (Germany), which had among his key representatives the likes of Klee, Kandinsky, or Walter Gropius, the Bauhaus founder. The Bauhaus was an artistic and social movement that played a crucial role in taking aesthetics and design into everyday life worldwide. When Hitler took power in Germany, a diaspora of Bauhaus pioneering thinkers (Gropius, Van der Rohe, Brauer, among others) moved to United Kingdom, United States, and Israel. The circulation of the founding fathers made the vision and practices of the school spread all over the world, attracting several acolytes. The followers were able to learn the lessons of modernity, marrying beauty with soberness, functionality with form. The influence of this movement was strong, triggering multiple and unexpected outcomes across a variety of industries and domains. The Bauhaus left a profound imprint on the labour market, shaping a generation of painters, designers and architects, and disseminating its footprints in the activities and products of scores of design-driven companies, contributing to the appreciation of style as a canon of practice across a wide variety of organizational endeavours.

Over the past decade, organizational and management scholarship has been paying increasing attention to the domain of aesthetics, related to judgements of style and beauty. Strategy scholars have exposed the central role of design choices for coupling function and aesthetic form to fuel competitive advantage, and design-driven innovation has emerged as a distinct category to evoke the combination of form and function in product market settings. This scholarship has taught us that great strategies have great style. They thrive on the dual aesthetics of the poetry of the image and the prose of numbers. They stem from long term aesthetic commitments that shape the whole organization, its vision, workforce and operations, upstream and downstream the value chain. If we asked a group of design experts to name a bunch of companies that are a good representative of this aesthetic commitment towards marrying business and beauty, they would probably mention such iconic brands as Herman Miller, Apple, Alessi, Vitra, Bang \& Olufsen, Swatch and others. What do these companies have in common? I think what they share is the devotion to a stylistic canon.

By canon, I mean a combination of rules, principles and practices that inform the company's organizational routines and strategic choices. With no ambition to comprehensiveness, I wish to highlight 4 features of this canon - first, the use of repositories of styles. The careful creation of a collection of artifacts and objects, ultimately called the museum, is almost invariably a distinctive feature of aesthetically oriented companies. Corporate museums are not primarily conceived for the visitors, who usually are very few and sometimes do not even pay the ticket, but they are working spaces for absorbing, codifying and diffusing 
the insights springing out from the collections. The Vitra museum space, for instance, is central to encircling employees into an aesthetic atmosphere that imprints itself on the company identity. At Alessi, the 'museum' is a working space for the articulation of new projects and the sedimentation of old ones into the organizational memory of the company. Second, the relentless search for and cultivation of designers and other aesthetically inclined creative talents. An exemplar in this respect is 'the tea and coffee award' by Alessi, a competition among artists to design a tea and coffee cup, eventually produced in limited series. The goal of the contest is not the product, but the identification of talents to recruit. The care for talent is complemented by great emphasis on space, ambiance and atmosphere. Swatch deliberately deploys a small team of creatives in iconic cities such as Venice, New York, Milan renowned for their aesthetic appeal. Third, a strong aesthetic culture which is often nurtured through collective rituals that unite people in the pursuit of beauty. In these contexts, professionals often work in 'clan-like' organizational structures that are kept together not only by the materiality of their working life but by their passion for higher pursuits, reflecting a urge to be surrounded by the aesthetic sensations of beauty, not as a substitute for the rigors of analysis but as a property of them. Fourth, a strong focus on the 'flagship store', typically designed by archistars, to convey symbolic meaning and identity claims. The store encapsulates the company style and makes it easily referable to the company image. At the same time, it is a purveyor of the company aesthetic commitment that has an immediate resonance with its visitors.

Aesthetics shows rather than tells delights rather than instructs. The effects are immediate, perceptual and emotional. Building a stylistic canon requires going beyond the utilitarian rationalization of aesthetics. It requires honouring beauty not only as an instrument of utility but also as a fundamental human aspiration because, as Jim March reminded us, 'profoundly useful ideas about management and organizations are more likely to come from the playful pursuit of artistry in ideas than from an ambition to be helpful to managers or their social overseers' (March 2013).

Gianni Lorenzoni 


\title{
THE AESTHETIC TURN IN STRATEGY: CREATING VALUE WITH STYLE
}

\author{
Gino Cattani, Simone Ferriani, Frédéric Godart \\ and Stoyan V. Sgourev
}

Style is a simple way of saying complicated things

-Jean Cocteau

\section{INTRODUCTION}

Steve Jobs is frequently invoked as an example of a 'visionary' leader in business. But what is it about his 'vision' that was so distinctive? In his famous speech at Stanford University in 2005, he gave a clue - the calligraphy lessons he took at Reed College in 1972. Seemingly devoid of any practical utility at the time, the accumulated skills and enhanced aesthetic sensitivity acquired from exposure to calligraphy were put into use a decade later when creating the first Macintosh computer. Its elegant design would give rise to a full-blown commitment to aesthetics that became the hallmark of Apple. Calligraphy is not merely a way of writing, but a philosophical process articulated through the careful configuration of brush strokes, which combines poetry, literature and painting. That this complex art form would imprint itself on one of the most celebrated narratives of business success is a testament to more than the role of chance in life. It embodies the propensity to reconsider the role of aesthetics in business, and the recognition that, to paraphrase Albert Einstein, the greatest managers are also artists.

Aesthetics and Style in Strategy

Advances in Strategic Management, Volume 42, 1-15

(C) Gino Cattani, Simone Ferriani, Frédéric Godart, and Stoyan V. Sgourev. Published by Emerald Publishing Limited. This chapter is published under the Creative Commons Attribution (CC BY 4.0) licence. Anyone may reproduce, distribute, translate and create derivative works of this article (for both commercial \& non-commercial purposes), subject to full attribution to the original publication and authors. The full terms of this licence may be seen at http://creativecommons.org/ licences/by/4.0/legalcode

All rights of reproduction in any form reserved

ISSN: 0742-3322/doi:10.1108/S0742-332220200000042024 
Aesthetics is the art of appreciation of beauty (Levy \& Czepiel, 1974). It underlies value judgements (Holbrook \& Hirschman, 1982) and encompasses a variety of practices that use line, form, tone, colour and texture in order to create beauty and arouse an emotional reaction in viewers (Bloch, 1995; Veryzer, 1993). Csikszentmihalyi and Robinson (1990, p. 178) characterize aesthetic responses as 'a state of intense enjoyment characterized by feelings of personal wholeness, a sense of discovery, and a sense of human connectedness'.

The importance of aesthetics transpires in the tendency of consumers to appreciate beautiful objects as 'sacred' or 'singular' (Karpik, 2010, p. 3). Objects are 'sanctified' when they are highly valued by consumers and are treated reverentially as extensions of oneself (Belk, Melanie Wallendorf, \& Sherry, 1989). They are often attributed qualities of uniqueness, authenticity and singularity (Cornfield \& Edwards, 1983). Some craft products are so venerated in popular culture that users regard them as singular and incommensurable.

We are accustomed to aesthetic experiences when viewing a painting or attending a concert. We are less used to celebrating the beauty of organizational practices, such as appreciating when an assembly line runs smoothly, or paying attention to the 'the pipes that are connected with delicate attention to fit' (Augier \& March, 2008, p. 409). And yet companies make aesthetic choices regularly, deciding on the look of their products, the shape and colours of the logo, the design of their commercial space or the dress code of employees. One of the less heralded tasks of management is in facilitating the aesthetic choices that shape organizational performance and firm survival. For example, stylistic considerations may distinguish a firm's products from those of its competitors, thereby contributing to achieving not only brand recognition but also success in the marketplace.

Aesthetic choices have a symbolic function that influences how a product is perceived and evaluated. Images of elegance, class and durability may originate in choices on the look and feel of new products. These sensory experiences provide grounds for consumer judgements and enable the products to connect with potential buyers. Unsurprisingly, aesthetic judgements occupy centre stage in a range of cultural and economic domains. For example, Barthes (1983) observes that Japanese cuisine is decentralized in natureand highly visual. No Japanese dish has a clear centre similar to the traditional arrangement of centrepiece and side dishes in Western cuisine. Whether in technology or cuisine, aesthetic judgements are based on shared values and cultural beliefs, giving form to complex visual patterns and skills that are encoded in material objects (Baxandall, 1985), including consumer goods, works of art or the game of chess. In chess, what makes a game exciting or memorable is not its mathematical depth in terms of the permutations of possible moves at any given moment, but how interesting and visually appealing are the arrangements of the pieces on the chessboard. In much the same way, photography provides the opportunity to articulate artistic intentions through aesthetic (e.g., the pursuit of delicate nuance or contrast of colours) or technological (e.g., the use of digital or analog technology) choices (Aspers, 2001). 
What we are experiencing today is the pinnacle of a process of aesthetization of the economy with ample implications for consumption habits and social identities. As Postrel (2003, p. 5) observes: 'Aesthetics is not [...] limited to only a few settings or industries, or designed to communicate only power, influence, or wealth. Sensory appeals are everywhere, they are increasingly personalized and are intensifying'. Lipovetsky \& Serroy (2013) provide a rich overview of the historical process that led us to this point. It started in the mid-nineteenth century, when segments of capitalist societies began to integrate aesthetics by reorienting production and marketing choices. The aesthetic seduction of consumers, or what these authors define as 'artistic capitalism', originated with the ascent of new organizational forms, like the department store, decorated with expensive materials in the lush and dazzling Art Nouveau style. The use of elegant posters and forms of packaging aimed to embellish standardized products that differed little on quality.

The first half of the twentieth century witnessed the progressive separation of art and style from business, as the growing reliance on technology and price in marketing illustrates. During this period, efforts to combine style and function (such as the 'Wiener Werkstätte' cooperative of artists and designers) proved unsuccessful in finding an economically viable production method that would allow offering refined products at affordable prices. Things started to change in the 1960s, with the growing democratization of consumption and the interweaving of business and art in the 'Pop Art' movement. Using commercial images as an input for the creation of artworks - a practice associated most closely with Andy Warhol's style - the movement embodied the desire to suppress the boundaries between the economic and aesthetic domains, ushering in a tendency towards cultural 'hybridization'.

Since the 1980s, this tendency has accelerated, giving rise to an ever-increasing array of stylized products, intending to bolster emotional experience and brand attachment. The markings of this process are visible in the attempts of producers to move upmarket by making references to style, the rapprochement between luxury and art, the mixing of codes from high and low culture and the rise of new fashion houses. Competitive market forces are driving a relentless pursuit of beauty everywhere - from haute cuisine to luxury goods and craft products. These products 'serve an aesthetic or expressive rather than a clearly utilitarian purpose' (Hirsch, 1972, pp. 641-642). Art has become an instrument of legitimation, as testified by how prominent architects like Frank Gehry or business leaders like Steve Jobs are celebrated as 'visionary artists'.

More than 80 years ago, Chester Barnard (1938, p. 235) argued that management was 'aesthetic rather than logical', described by terms, such as 'feeling, judgement and sense'. Yet, it is only recently that strategy scholars have begun to pay attention to the domain of aesthetics. There is growing recognition that many organizational decisions are made based on aesthetic principles rather than on efficiency or rationality. As Hansen, Ropo and Saur (2007, p. 546) point out, we rely on aesthetic meanings to guide our actions just as much as we rely on logical reasoning; these meanings are as pervasive in work settings as they are in everyday life. 
One example of this principle is Dobson's (1999) categorization of managers as technicians, moral managers and aesthetic managers. With the emergence of the aesthetic management paradigm, managers increasingly view their role as artistic in nature, seeking craft-based excellence rather than the mere pursuit of profit. This quest for excellence is a distinctive characteristic of Steinway \& Sons' relentless commitment to craftsmanship in an effort to enhance the perceived uniqueness of its pianos, at the risk of forfeiting profits in the short run (Cattani, Dunbar, \& Shapira, 2017).

Firms are nowadays confronted with a cultural landscape that encourages the consumption of styles rather than goods. This poses complex identity choices across audiences with different stylistic preferences and evaluation criteria (Cattani, Ferriani, \& Allison, 2014; Godart, Seong, \& Phillips, 2020; Wijnberg, 1995). The rise of aestheticism in culture and product design, and the strategic dilemmas it poses, is what motivates this volume, as the first systematic survey of the interface between style and strategy. We articulate the foundations of what can be defined as the 'aesthetic' turn in strategy.

\section{STYLE IN THIS VOLUME}

A necessary first step in documenting the role played by aesthetics in business is to elucidate the concept of style. Widely used across academic disciplines, such as art history (Sauerländer, 1983) and anthropology (Hegmon, 1992), style is yet to find its proper place in strategy and management.

Designating how something is done, created or performed, style is distinct from function. A work of art may come into being in many different ways while serving the same function. For example, a writer may choose to employ sophisticated or more casual language; an artist may use different mediums to express an idea or display a chromatic preference. Style can thus be defined as 'a durable, recognizable pattern of aesthetic choices' (Godart, 2018, p. 103). It is this consistency over time that allows us to distinguish between a Fellini and a Bergman movie, Mughul and Roji gardens, Cantilever and Knoll lounge chairs, or between the leadership styles of Lee Iacocca and Steve Jobs.

As Postrel (2003) rightfully observes, judgements of style are not optional addons to more essential functionality, but are constitutive parts of all human creations. Aesthetic experiences matter to people's sense of self and to how they experience meanings and emotions. A style does not belong solely to its author, as it emerges in interaction and negotiation with the audience to which it is addressed.

We divided the volume into three parts, capturing the different perspectives that contributors develop in exploring the interface between strategy and style. Some of them focus on the demand side and others on the supply side. The first part, Stylistic Production, offers insights into how producers make stylistic choices that shape their identity and performance. The second part, Stylistic Evaluation, switches to the demand side, examining the reception of styles by social audiences. The third part, Stylistic Reflection, consists of several interviews 
with prominent scholars that discuss how style and beauty inform strategic choices and managerial scholarship. These conversations provide insights on how to pursue an aesthetically informed research agenda in the strategy domain.

The first section of this book, Stylistic Production, has four chapters. In Chapter 1, Giovanni Formilan discusses the notion of style as an expression of the identity of a producer. The author articulates style as a recurrent combination of visible elements of a producer's activity that can be used comparatively within contexts or be transferred across contexts. As such, style has an important function as a normative and classificatory device in markets, which structures and controls career trajectories of cultural producers. While the style of a musician is an expression of her identity, it also influences that identity in facilitating certain career moves and experiments with content and discouraging others.

The empirical analysis confirms a long-standing observation in organizational research that stylistic consistence tends to be rewarded in markets. The caveat, however, is that in the creative industries there is a premium on creativity, as it is the primary means of differentiation for producers (Caves, 2000). Accordingly, Formilan finds that artists with a nonconformist but consistent style tend to occupy the highest positions in the Top-100 of electronic music. Although nonconformism is a less attractive pathway to consecration than conformism, artists can still make it to the top if the collection of diverse elements that define their style exhibits a recognizable, consistent pattern. The findings clarify how style can be used as a source of competitive advantage - distinct from, but potentially complementing, producers' internal and external strategies.

In Chapter 2, Frédéric Godart, Kim Claes and Stoyan V. Sgourev examine an important objective for firms and managers: finding the right type and level of aesthetic and technological complexity to pursue in their product offerings to multiple audiences. High aesthetic complexity - the number of design combinations in watches - increases the probability of receiving a professional award, but may be less appreciated by customers who put a premium on the technological complexity of the watches. Navigating different principles of excellence and the expectations of multiple audiences is a form of competence that is increasingly pertinent in the current business environment and is applicable across domains. Consider the four basic culinary dimensions, as defined by Chef Daniel Humm. First, the dish must be delicious. Second, the dish must be beautiful. Third, the dish must be creative, add a new element. Fourth, it must reveal an intention, a materialized reason for being. The key observation of Chef Humm is that the dimensions work against each other. ${ }^{1}$ Thus, creativity and deliciousness do not go hand in hand, yet they both need to be present. These observations are useful as they remind us that the quest for beauty is not self-sufficient and that beauty is a principal component in a system that also includes other dimensions that must be harmoniously aligned to embody the identity of the producer.

The instrumental use of style to create and project a personal identity in a social domain is on display in Dubois and Anik's study of the practice of wearing

\footnotetext{
${ }^{1}$ Netflix, 'Seven Days Out', Episode 2: 11Eleven Madison Park, 2018.
} 
high heels (Chapter 3). There is hardly an object that better illustrates the power of style to transform ordinary materials into symbols of power and prestige. High heels have been associated for centuries with a privileged social position; a central element in a game of 'seeing' and 'being seen' at the royal court, where individual vision is structured by social distinctions, such as one's position in a 'noble' hierarchy (Hillman, 2006). Social status and power are interwoven in many domains, such as in art or fashion, long dominated by an aristocracy that asserted its superiority over the inferior social classes through the consumption of extravagant products with limited comfort or practical use. That high heels can be used to raise one's social status is a key reason why in past centuries their wearing has been normatively regulated. Dubois and Anik expose the interplay between power, status and style in experimental work that clarifies how the stylistic choices of consumers can both reflect their sociopsychological state and impact their behaviour in the marketplace. Their studies show that wearing heels (vs. flat shoes) makes individuals feel and behave more powerfully by thinking more abstractly and by taking more actions, but only when heels are worn conspicuously (i.e., the wearer knows the observer sees them).

The question of leadership style is central in strategy. The traditional approach to it is to identify the style of a leader in his/her decision-making process (Helmich \& Erzen, 1975). In Chapter 4, Nikita Basov, Artem Antonyuk and IIna Hellsten revisit the notion of a leader's style by using a rich dataset of interactions in creative collectives. They distinguish three styles depending on the leader's position in the collective: Critic, Integrator and Organizer. They relate these styles to the positions of leaders within networks, proposing that a style originates from the intersection of social and semantic network positions. This resonates with White's (2008) understanding of style as emerging from networks and stories. Styles are both expressions of identities and identities in their own right because they generate social action (White, 1993). Styles encompass networks of social ties and meanings (Fontdevila, Opazo, \& White, 2011), facilitating certain strategic decisions, such as with whom to form a strategic alliance.

Strategy scholars recognize the central role of narratives in the construction of organizational identities. Storytelling is an important strategic asset that can be leveraged to inspire employees, convince investors or engage customers' attention. In Chapter 5, Cutolo, Ferriani and Cattani discuss the opportunities that advancements in computational linguistics present to analyze the stylistic elements that make a story convincing. While previous studies have examined the composition and temporal construction of narratives, their focus is on the stylistic conventionality of entrepreneurial narratives - i.e., the tendency to include topics that are shared by other entrepreneurs in the same product category. Using topic modelling, the authors explore the stories of craftsmen who sell their products on Esty, the largest digital marketplace for handmade items, analyzing how the conventionality of narratives influences performance. Their findings attest that effective narratives have enough conventional features to align with audience expectations, but preserve uniqueness to arouse the audience's interest.

The second section of the book, Stylistic Reaction, contains four chapters. In Chapter 6, Micki Eisenman and Tal Simons discuss the relevance of aesthetic 
innovation to the institutionalization of the competitive landscape of three industries: cars, speciality coffee and personal computers. The authors elucidate the mechanisms by which firms make aesthetic choices in order to connect their products to the identities of their audiences, eliciting emotional reactions to products. Stylistic and design-driven choices stimulate consumption not only by inducing fashion-like consumption patterns but also by promoting deeper personal connections between products and audiences. The three cases suggest that aesthetic innovation matters when it engenders emotional reaction among stakeholders and that this reaction drives the diffusion and institutionalization of innovation. This chapter draws on a large body of work on the creative industries to illuminate the strategic route to aesthetic innovation.

In Chapter 7, Paola Cillo, Joseph C. Nunes, Emanuela Prandelli and Irene Scopelliti draw attention to the role of gatekeeping audiences - intermediaries between producers and consumers (Smits, 2016), in influencing stylistic dynamics. They draw on a unique dataset of visual cues from fashion magazines in Italy and France, and critical appraisals from prominent media channels. While fashion designers are believed to be 'dictators' who define seasonal fashion trends in a top-down manner, these authors demonstrate that designers tend to follow and adapt to the reactions of critics. The analysis demonstrates that the stylistic choices of designers depend on the assessments of styles of competing designers, illuminating how design houses react to each other to articulate singularity.

Style also influences perceptions of competition among firms. In Chapter 8, Daniel Sands contributes along these lines by examining how the aesthetic composition of competition affects consumer perceptions of quality. Sands develops a theoretical framework explaining how a product's stylistic similarity to popular competitors results in negative consumer evaluations. Using more than 75,000 Rotten Tomatoes consumer evaluations of 123 feature films released in the US during 2007, he finds that during a movie's opening week, movies that are stylistically similar to the top-performing box office movie are evaluated less favourably. He provides evidence suggesting that this negative effect tends to persist in later periods due to social conformity pressures and that there is also reduced demand for those movies that are stylistically similar to the top box office movie. By showing how stylistic similarity negatively affects consumer perceptions of quality, this chapter sheds light on the importance of stylistic considerations for decisions on timing-of-entry and positioning.

In Chapter 9, Alexander Hoppe investigates the core/periphery structure of the global fashion industry, paying close attention to the position of cities in the global value chain. While Cattani and Ferriani (2008) used collaborative networks to explore the social structure of creativity, Hoppe argues that collaborative networks are themselves embedded in a hierarchy of cities, with Paris, New York, Milan and London at the core, and other cities at the periphery (Godart, 2014). Fashion houses located at the periphery need to abide by norms defined by fashion houses at the core to avoid being perceived as 'unfashionable' and to enhance their appeal to high-status audiences. The author shows that norms 
encourage the pursuit of a balance of imitation and distinction, even though institutional constraints lead houses to become associated with local gatekeepers that drive down their status.

The third section of this book, Reflections on Style, consists of interviews with five prominent scholars - Candace Jones, Gianni Lorenzoni, Virginia Postrel, Davide Ravasi and Antonio Strati - discussing the interface between aesthetics and strategy, the role of beauty in management, the ways of making research more visually appealing and future scholarship on beauty and style. They all agree that aesthetic considerations are of strategic importance to firms in a variety of industries where consumers increasingly value beauty and are willing to pay a premium for products evoking emotions. As a key source of differentiation, beauty is an intangible asset that is not easy to imitate by competitors. It would be difficult to explain the success of firms, such as Apple, Alessi, Audemars Piguet, IDEO or Steinway, without accounting for the unique design of their products. Virginia Postrel notes that expectations for aesthetic quality have increased across industries, while Davide Ravasi identifies this process at the organizational level - a beautiful workplace helps to attract and retain talented people, stimulating their ability to innovate. Antonio Strati notes that the connection between beauty and competitive advantage traverses the entire organization, from its style of communication with internal and external audiences to its product design, work environment and strategy. At the same time, Candace Jones reminds us that the question of beauty is still located on the periphery of strategy, presenting an opportunity for scholars to further explore how firms may apply beauty and style in their strategies for value creation. Gianni Lorenzoni stresses the role of beauty as an evaluative device that speaks to one's sense of self. He encourages us to embrace aesthetic principles in our managerial research in a manner evocative of James March's celebration of scholarship committed to sustaining an institution of learning as an object of beauty and an affirmation of humanity.

To enable the aesthetic turn in strategy, our interviewees propose a set of research questions. Davide Ravasi is curious about the factors shaping our perceptions of beauty and style, and how this knowledge can be put into practice. Candace Jones directs attention to how perceptions of beauty interact with new materials and technologies in reshaping business landscapes. For example, in the fashion industry, the dichotomy between handmade and machine-made is increasingly blurred by the emergence of new technologies and materials that afford unprecedented possibilities in terms of shapes and designs. Along similar lines, Virginia Postrel emphasizes the need to better understand the connection between beauty and the tools used to create it, giving as an example how the aesthetic nature of silk production encouraged mechanical ingenuity. Antonio Strati reminds us that aesthetic factors place the human side of organizational life at the centre of strategy. The adoption of a new humanistic paradigm implies leadership with aesthetic sensibility, whose objective is to create not only a healthier work environment. Gianni Lorenzoni calls for a deeper appreciation of how aesthetic canons form and become part of an organizational culture informing strategic and managerial practices. He advocates for scholarship 